\title{
Sero-Prevalence of Contagious Caprine Pleuropneumonia in Goats in Afgoye District Lower Shabelle Region, Somalia
}

\section{Omar Mohamed Abdi1*, Abdi Majiid Said Jama, Abdirahman Abdullahi Jama $^{1}$, Ahmed Ali Omar ${ }^{1}$ and Abdirahman Bare Dubad ${ }^{2}$ \\ ${ }^{1}$ Collage of Veterinary Medicine, Abrar University, Somalia \\ ${ }^{2}$ Faculty of veterinary medicine and Animal husbandry, Somali National University, Somalia}

*Corresponding author: Omar Mohamed Abdi, Collage of Veterinary Medicine, Abrar University, Mogadishu, Somalia, Email: omarmohamedvet@gmail.com

\section{Research Article}

Volume 5 Issue 2

Received Date: October 12, 2020

Published Date: November 11, 2020

DOI: $10.23880 /$ oajvsr-16000203

\section{Abstract}

Background: Contagious caprine pleuropneumonia (CCPP), caused by Mycoplasma capricolum subsp. Capripneumoniae (Mccp), is one of the most important goat diseases causing high morbidity and mortality, these results in heavy economic losses to countries like Somalia, which is a country affected the civil war of the 1990s.

Objective: Generally, the disease presence has been reported in the country. However, there is no quantitative data on the prevalence and distribution of the disease has been scientifically reported in the country.

Methods: A cross-sectional study was conducted from September 2019 to June 2020 in three villages of Afgoye district of Somalia to assess the seroprevalence and identify the associated risk factors for the occurrence of the CCPP. The risk factors considered included sex, age, and locations.

Results: A total of 100 blood samples were collected and evaluated by Capri-Latex Agglutination Test (Capri-LAT). A total of 49/100 (49\%, CI 95\%: (38.86\%-59.2\%) goats were seropositive for anti-CCPP antibody. The epidemiological risk factors considered, sex, age and locations, were not significantly associated with the CCPP sero prevalence ( $>0.05)$. However, the sero positivity was slightly higher in female (51\%, 95\% CI: 39.8-62.6), >3 years old goats (86.3\%, 95\% CI: 48.9-87.4) and Markazka village (56\%, 95\% CI: 41.3-70.0) compared to male (40\%, 95\% CI: 19.1-63.9), 1-3 years old (57.5\%, 95\% CI: 40.973.0), and Shareeco (43.8\%, 95\% CI: 19.8-70.1) and Siinka (41.2\%, 95\% CI: 24.7-59.3) villages, respectively.

Conclusion: The present study indicates the prevalence of CCPP in the studies areas and this requires practicable measures to be put in place towards the control of the disease.

Keywords: CCPP; Sero-prevalence; Capri-LAT; Risk Factors; Somalia

Abbreviations: CCPP: Contagious Caprine Pleuropneumonia; Mccp: Mycoplasma capricolum subspecies capripneumoniae.

\section{Introduction}

Contagious caprine pleuropneumonia (CCPP) is one of the highly infectious and serious respiratory diseases of goats clinically characterized by coughing, respiratory distress, and very high morbidity and mortality rates [1]. The disease is caused by the smallest fastidious bacteria, member of the Mycoplasma genus- usually Mycoplasma capricolum subspecies capripneumoniae (Mccp); taxonomically grouped as one of the members of the Mycoplasma mycoides cluster [2]. 


\section{Open Access Journal of Veterinary Science \& Research}

Contagious caprine pleuropneumonia (CCPP) is an important economical, classical transboundary animal disease which can cause mortality rates up to $80 \%$ insusceptible flocks of goats [3]. Goat plays an important role in the livelihoods and food security of many countries as a source of milk, meat and wool [4]. Including Somalia, and also play a critical role in the livelihoods of the traders, for instancein the horn of Africa the trade of goat is geographically dispersed in Kenya, Somalia, Djibouti, and Ethiopia. However, it is facing various problems including diseases, feed scarcity, poor management, inadequate marketing infrastructure, and Veterinary service [5] of these factors; diseases are wide spread and have a significant impact on the production of goat [6]. Therefore the aim of this study is to estimate the prevalence of CCPP in Lower shabelle region Somalia using CapriLAT.

\section{Methodology}

\section{Study Area}

The Lower Shabelle region lies to the west, northwest, and southwest of Mogadishu. It is bordered to the south by the Juba region, to the east by the Indian Ocean and Mogadishu, the Middle Shabelle region to the north, and the Bay region to the west. The topography is composed of plains, coastal areas, and semi-desert stretches such as the Brava district. The region comprises eight districts; one of them included this study [7]. This area was selected purposively, due to security and accessibility to this district.

\section{Study Design}

Acros-sectional study design that investigate the seroprevalence of contagious caprine Pleuropneumonia and Some associated risk factors in Afgooye district lower Shabelle Region Somalia.

\section{Study Population}

The study population was Goat that is reared on an extensive husbandry system. Animals were allowed to graze freely at day time and kept in poorly constructed fenced barn or house at night. Goats were sampled accordingly with no history of vaccination by asking the owners and according to age, three age groups: $<1 \mathrm{yr}$ and 1-2 years, 2-3 years, and $>3$ years.

\section{Sample Collection}

A total of 100 blood samples of goats were collected From September 2019 to June 2020, and involving randomly selected household and their goats. Approximately $5 \mathrm{ml}$ of a blood sample from the jugular vein of each animal using plain vacutainer tubes. The samples were labeled accordingly to identify each animal and transported it into the laboratory of the Abrar Research and Training Centre (ARTC). The samples were then centrifuged at $1500 \times \mathrm{g}$ for $5 \mathrm{~min}$, serum separated and kept at $-20^{\circ} \mathrm{C}$ for serological studies.

\section{Laboratory Examination (CapriLAT)}

The collected serum samples $(n=100)$ were tested for the presence of antibodies against Mccp using CapriLAT kit (Animal \& Plant Health Agency, Surrey, UK) as per manufacturer's instructions. Briefly, a spot of $20 \mu \mathrm{l}$ of serum was carefully dispensed onto one of 6 reaction cells of a black card using a micropipette. Latex reagent was well shaken before use and $20 \mu \mathrm{l}$ volumes was carefully put next to the serum spot and gently mixed by a wooden stick and spread out inside the reaction cell. The mixture was rocked for three minutes and degrees of agglutination were recorded as follows: strong clumping considered as (+++), clear agglutination as (++), fine agglutination as $(+)$ and no agglutination as (-) Positive and negative control sera were run with every 3-4 cards.

\section{Data Management and Analysis}

Collected data were entered, coded, and kept in a Microsoft ${ }^{\circledR}$ Excel spread sheet for Windows ${ }^{\circledR} 2013$ data base and then transferred to the SPSS Windows ${ }^{\circledR}$ version 23.

\section{Results}

The prevalence of CCPP was investigated in the goat population of Siinka, Markazka, and Shareeco under Afgoye District of the Lower Shebelle region. A total of 100 samples were investigated for CCPP through Capri-LAT test, the overall seroprevalence was 49/100 (49\%).

\section{Risk Factors Associated with CCPP}

The table below shows that sex is not statistically significant $(\mathrm{P}>0.504)$. However, due to the higher numbers of females in the herd composition, the female has $51 \%$ sero positivity while males have $40 \%$ seropositive.

According to age there is statistically significant $(\mathrm{P}<0.05)$, that middle age groups $(1-3$ years $)$ show high sero prevalence $(57.5 \%)$ while the advanced aged animal ( $>3 \mathrm{yrs})$ showed second highest seropositive. The least seropositive were detected at the younger one $<1$ year and below.

According to villages Markazka records the highest seropositive samples (56\%) it is followed by Shareeco $(43.8 \%)$, and the least is Siinka (41.2\%). However, there is a statistically insignificant $(\mathrm{p}=0.370)$ (Table 1$)$. 


\section{Open Access Journal of Veterinary Science \& Research}

\begin{tabular}{|c|c|c|c|c|c|c|c|}
\hline \multicolumn{2}{|c|}{ Variable } & $+/ N$ & Prevalence \% & 95\% CI: & P-value & Chi-square & 95\% OR: \\
\hline \multirow{3}{*}{ Villages } & Shareeco & $7 / 16$ & 43.8 & (19.8-70.1) & 0.99 & 0.03 & $1.1(0.3-3.7)$ \\
\hline & Markazka & $28 / 50$ & 56 & $(41.3-70.0)$ & 0.27 & 1.78 & $1.8(07-4.4)$ \\
\hline & Siinka & $14 / 34$ & 41.2 & $(24.7-59.3)$ & ref & & \\
\hline \multirow{2}{*}{ Sex } & Female & $41 / 80$ & 51.3 & $(39.8-62.6)$ & 0.52 & 0.81 & $1.6(0.6-4.3)$ \\
\hline & Mela & $8 / 20$ & 40.0 & $(19.1-63.9)$ & ref & & \\
\hline \multirow{3}{*}{ Age } & $1-3$ yrs & $23 / 40$ & 57.5 & $(40.9-73.0)$ & 0.00 & 8.2 & $4.1(1.5-10.8)$ \\
\hline & $>3$ yrs & $17 / 24$ & 86.3 & $(48.9-87.4)$ & 0.00 & 12.3 & $7.3(2.3-23.2)$ \\
\hline & $<1 \mathrm{yr}$ & $9 / 36$ & 25 & $(12.1-42.2)$ & ref & & \\
\hline \multicolumn{8}{|c|}{$+=$ Number of positive, $\mathrm{n}=$ Sample number, $\mathrm{CI}=$ Confidence interval, $\mathrm{OR}=$ Odds ratio } \\
\hline
\end{tabular}

Table 1: Prevalence of CCPP within each variable studied.

\section{Discussion}

The overall seroprevalence was 49/100 (49\%) were positive, Out of the reactive sera, 11 were strong positive $(+++), 15$ were of moderate agglutination $(++)$ and 23 showed weak reaction $(+)$. In the present study, a total of 100 samples were examined by Capri- LAT to record the seroprevalence of CCPP in goats in three villages under the Afgoye district lower Shabelle region Somalia. According to Sex seroprevalence of CCPP in goats was also carried out during this study, $51 \%$ seropositivity was observed among females and $40 \%$ in males, this results obtained refers that there was no sex difference in seroprevalence of CCPP this approves with findings of Kusiluka IJ, et al. [8]. In Tanzania; [9-12] in different parts of Ethiopia and [13] in Kenya who reported that CCPP is a highly contagious disease ingoat with irrespective of sex variation [14]. Base on the age of animals this study old age higher prevalence than young animals. This indicates that the highest seropositivity of $86.3 \%$ was recorded in the old age group of goats, while lower in young age $25 \%$ on Capri-LAT as they found [11,1517]. This reported older animals showed higher prevalence as compared to young animals because as with the increase in age, goats are exposed to various stress conditions due to (adverse weather, movement on long-distance and malnutrition) which can predispose an animal to disease.

During the current study, Markazka records the highest seropositive of CCPP (56\%) followed by Shareeco (43.8\%) and the least is Siinka (41.2\%) However, there is statistically insignificant $(p=0.370)$ because of these villages within the same agro ecological zone.

\section{Acknowledgment}

The authors would like to thank Dr. Ahmed A. HassanKadle, Dr. Abdalla Mohamed Ibrahim, Dr. Abdulkarim A. Yusuf and Abrar University for their support to carry out this work.

\section{References}

1. Thiaucourt F, Bolske G (1996) Contagious caprine pleuropneumonia and other pulmonary mycoplasmoses of sheep and goats. Revue Scientifiqueet Technique de l'OIE 15(4): 1397-1414.

2. Swai ES, Kaaya JE, Noah EY (2013) Antibody response to Mycoplasma capricolum subsp. capripneumoniae bacterium in small holder dairy goats in Tanzania. Trop Anim Health Prod 45(7): 1603-1608.

3. OIE (2008) Manual of diagnostic tests and vaccines for terrestrial animals (mammals, birds and bees). Contagious caprine pleuropneumonia. Office International des Epizooties (OIE), Paris France 2: 287296.

4. Chakraborty S, Kumar A, Tiwari R, Rahal A, Malik Y, et al. (2014) Advances in diagnosis of respiratory diseases of Small Ruminants. In: Kumar A, Tikoo SK, Malik P, Kumar AT, (Eds.), Respiratory Diseases of Small Ruminants, Vet Med Int pp: 08304.

5. Hirpa A, Abebe G (2008) Economic Significance of Sheep and Goats. In: Sheep and Goat Production Handbook of Ethiopia. In: Yami A, Merkel RC, (Eds.), Ethiopia Sheep and Goat Productivity Improvement Program (ESGPIP), pp: 2-3.

6. Mekuria S, Zerihun A, Gebre-Egziabher B, Tibbo M (2008) Participatory investigation of contagious caprine pleuropneumonia (CCPP) in goats in the Hammer and Benna-Tsemay Districts of Southern Ethiopia. Trop Anim Health Prod 40(8): 571-582.

7. UNSOM2 (1994) Planing and information unit of Somalia, pp: 1-2. 


\section{Open Access Journal of Veterinary Science \& Research}

8. Kusiluka IJ, Semuguruka WD, Kazwala RR, Ojeniy B, Friis NF (2000) Demonstration of Mycoplasma capricolum subsp. Capripneumoniae and Mycoplasma mycoides subsp. mycoides, small colony type in outbreaks of caprine pleuropneumonia in eastern Tanzania. Acta Vet Scand 41(3): 311-319.

9. Eshetu L, Yigezu L, Asfaw Y (2007) A study on Contagious Caprine Pleuropneumonia (CCPP) in goats at an export oriented abattoir, Debrezeit, Ethiopia. Trop Anim Health Prod 39: 427-432.

10. Mekuria S, Asmare K (2010) Cross-sectional study on Contagious Caprine PleuroPneumonia in selected districts of sedentary and pastoral production systems in Southern Ethiopia. Trop Anim Health Prod 42(1): 6572.

11. Bekele T, Asfaw Y, Gebre-Egziabeher B, Abebe G (2011) Sero-prevalence of contagious caprine pleuropneumonia in Borana and Guji low lands, Southern Ethiopia. Ethiop Vet J 15(2): 69-76.

12. Yousuf E, Melaku A, Bogale B (2012) Sero-prevalence of contagious caprine pleuropneumonia in Dire Dawa provisional administrative council, Eastern Ethiopia. J Vet Med Anim Health 4(7): 93-96.

13. Kipronoh K, Ombuib J, Binepald Y, Wesongae H, Gitongae E, et al. (2016) Risk factors associated with contagious caprine Pleuropneumonia in goats in pastoral areas in the Rift Valley region of Kenya. Prev Vet Med 132: 107112.

14. OIE (2018) OIE-Listed diseases 2018. OIE, World Organisation for Animal Health.

15. Regassa F, Netsere M, Tsertse T (2010) Sero-Prevalence of contagious caprine pleuropneumonia in goat at selected woredas of Afar region. Ethiop Vet J 14(1): 8389.

16. Lakew M, Sisay T, Ayelet G, Eshetu E, Dawit G, et al. (2014) Serprevalence of contagious caprine pleuropneumonia and field performance58 of inactivated vaccine in Borana pastoral area, southern Ethiopia. Afr J Microbiol Res 8(24): 2344-2351.

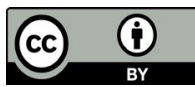

